\title{
Therapeutic Techniques in Rehabilitation of Core Stability Muscles among Patients with Mechanical Low Back Pain
}

\author{
Azzam Alarab, Hamza Shaheen
}

\begin{abstract}
The study was designed to compare between the effect of strengthening exercises and mobilization techniques among patients with mechanical low back pain. Sixteen participants were included in this study, three patients for each group were excluded. They were classified into two groups. Group A, strengthening exercises, therapeutic massage, and group B, mobilization techniques, therapeutic massage. Each group had three sessions per week, for four weeks. The participants were assessed by Visual Analogue Scale (VAS) and Oswestry Disability Index (ODI). Independent samples were collected, t-test was used to study the similarity of demographic data between groups, Wilcoxon Signed Ranks Test was used to study the change between pre- and post-treatment. The MannWhitney test was used to study the comparison between the two treatments. The comparison revealed that for VAS there was a significant difference between groups in term of the strengthening exercises group $(P>0.05)$. For ODI, there were no statically significant differences between groups $(P<0.05)$, but the impact of both techniques suggests that strengthening exercises have a higher effect comparing to mobilization techniques on pain. The study indicated that the strengthening exercises were more effective than mobilization techniques on pain. And finally, the study revealed that there was no significant difference between both groups on ODI.
\end{abstract}

Index Terms - Strengthening exercises, Therapeutic massage, Mobilization techniques, Mechanical low back pain.

\section{INTRODUCTION}

In chronic low back pain (LBP), $90 \%$ of cases were nonspecific, whereas $5-10 \%$ of cases were specific in origin, like degenerative conditions, inflammation, infection, and neoplasm. Studies have reported the prevalence of chronic LBP is increasing linearly from the third decade of life to 60 years of age, and more common in women [1].

Chronic LBP is associated with sleep problems, including a greater amount of time needed to fall asleep, disturbances during sleep, a shorter duration of sleep, and less satisfaction with sleep. In addition, a majority of those with chronic low back pain show symptoms of depression or anxiety [2].

Exercises are used to strengthen muscles, increase soft tissue stability, restore range of movement, improve cardiovascular conditioning, increase proprioception, and reduce fear of movement as part of a cognitive behavioral or progressive exposure program. Strengthening exercises are intended to directly and promptly diminish and eliminate

Published on August 31, 2020.

Azzam Alarab, Palestine Ahliya University, Palestine.

(corresponding e-mail: azzam @ ${ }^{\circledR}$ paluniv.edu.ps)

Hamza Shaheen, Palestine Ahliya University, Palestine. patients' symptoms by providing beneficial and corrective mechanical directional end-range loads to the underlying pain generator [3].

Amy Burleson Sullivan and colleagues reported that the role of exercise and types of exercise in the rehabilitation of chronic pain: specific or nonspecific benefits. As a finding they found there is agreement that exercise "helps" in the treatment of chronic pain, but it is still not clear exactly which factors or particular types of exercises may be attributed to such improvements [4].

Therapeutic massage incorporates a variety of advanced modalities that enhance the body's natural restorative functioning. Light to firm touch is used to release tension, relax muscles, increase blood and lymph circulation, and impart a sense of calm [5]. The application of massage therapy in patients with chronic nonspecific low back pain could promote benefits in terms of the level of pain reduction, lumbar spine mobility, and disability improvement [6].

Mobilization is one of many conservative treatment's therapists use for low back pain. In this method, the therapist applies a low velocity, repetitive movement to the spine. It is a passive treatment so the patient doesn't usually participate in any way [7].

Ian D. Coulter and colleagues reported that manipulation and mobilization for treating chronic low back pain, they found there is moderate-quality evidence that manipulation and mobilization are likely to reduce pain and improve function for patients with chronic low back pain; manipulation appears to produce a larger effect than mobilization. both therapies appear safe. Multimodal programs may be a promising option [8].

In the literature, there are few studies on the effect of strengthening exercises and mobilization techniques among patients with mechanical low back pain. and few studies have not examined the effects of this treatment on pain and function. Therefore, the study was done.

\section{METHODS AND MATERIALS}

\section{A. Study design}

This study was conducted in the Al-Abeer Physiotherapy Center, Hebron. An experimental study of mechanical low back pain. A total of sixteen patients would be randomly divided into two groups, three patients for each group were excluded in this study. Group (A) 5 patients were included, they were given strengthening exercises with a therapeutic massage and group (B) 5patients were included, they were given mobilization techniques with a therapeutic massage. 
Patients were selected according to inclusion and exclusion criteria. Written informed consent was taken and the whole study was explained to the participated patients. The targeted patients were assessed by the Visual Analogue Scale (VAS) and Oswestry Disability Index (ODI). Inclusion criteria were as follows: 1) Age group between 2050 years, 2) Both male and female participants, 3) A dull ache to a stabbing sensation in the lumber region. 4) Straight leg raises and femoral stretch leg positive, 5) Diagnosed sub-acute and chronic low back pain, 6) Pain at least 4 according to VAS. Exclusion criteria were as follows: 1) Rheumatoid disease, 2) History of vertebral fracture, 3) History of spinal surgery, 4) Spondylitis.

Group A: Follow these treatment protocols:

- $\quad$ Strengthening exercises

Therapeutic massage

Group B: Follow these treatment protocols:

- Mobilization techniques

- Therapeutic massage

\section{B. Statistical analysis}

The SPSS 24.0 software (Statistical Package for Social Sciences) was used to study the difference in groups and within groups. Descriptive and frequency statistics were used to study the main characteristic of the sample. Means, standard deviation, and percentages. Continuous variables were given as mean \pm standard deviation while categorical variables were given as number and percentage. Independent samples t-test (or independent t-test for short) was used to study the similarity of demographic data between groups. Wilcoxon Signed Ranks Test was used to study the change between pre- and post-treatment. $G^{*}$ Power software version 3.1.9.4. was used to calculate the effect size of the Wilcoxon Signed Ranks Test. Power analysis for a Wilcoxon signed-rank test was conducted in $\mathrm{G}^{*}$ Power to determine a sufficient sample size using an alpha of 0.05 , a power of 0.80 , a large effect size $(\mathrm{dz}=0.8)$. Additionally, Power analysis for a Wilcoxon signed-rank test was conducted in $G^{*}$ Power to determine a sufficient sample size using an alpha of 0.05 , a power of 0.80 , a medium effect size $(\mathrm{dz}=0.5)$. Also, Power analysis for a Wilcoxon signed-rank test was conducted in $G^{*}$ Power to determine a sufficient sample size using an alpha of 0.05 , a power of 0.80 , a small effect size $(\mathrm{dz}=0.2)$. The MannWhitney test was used to study the comparison between the two protocols.

\section{Figures}

As said, to insert images in Word, position the cursor at the insertion point and either use Insert | Picture | From File or copy the image to the Windows clipboard and then Edit | Paste Special | Picture (with "Float over text" unchecked).

The authors of the accepted manuscripts will be given a copyright form and the form should accompany your final submission.

\section{RESULTS}

Ten participated patients of mechanical low back pain considered the inclusion criteria and were included in the study. Following the data collection, the subjects were allotted into two groups, Group (A) strengthening exercises with a therapeutic massage and group (B) mobilization technique with a therapeutic massage. During 4 weeks of protocol 5patients were in group A and 5patients were in group B. Independent samples were collected and a t-test was used to study the similarity of demographic data between groups. The average weight for group A was 73.2 $\mathrm{Kg}$, while the average weight in group B was $76.8 \mathrm{Kg}$. The data shows that the average height in group A was $165.6 \mathrm{~cm}$, while the average height in group B was $172.4 \mathrm{~cm}$. According to the Age, the average age for group A was 36.6 years, and the average age for group B was 46.2 years. On the other hand, the average BMI for group A was 26.6 while it was 25.8 for group B. There were no statistically significant differences between group A in terms of body weight, height, age, and body mass index (BMI) values. Table I shows the characterizations of the included samples.

TABLE I: A COMPARISON FOR THE TWO GROUPS' DEMOGRAPHIC DATA.

\begin{tabular}{ccccc}
\hline \hline Variables & $\begin{array}{c}\text { Group A } \\
\text { Strengthening } \\
\text { exercises \& } \\
\text { therapeutic } \\
\text { massage } \\
\text { Mean (SD) }\end{array}$ & $\begin{array}{c}\text { Group B } \\
\text { Therapeutic } \\
\text { massage and } \\
\text { mobilizations } \\
\text { Mean (SD) }\end{array}$ & t-value & p-value \\
Age & $\begin{array}{c}36.6 \\
(11.6)\end{array}$ & $46.2(6.3)$ & -1.625 & 0.143 \\
Weight $(\mathrm{Kg})$ & $\begin{array}{c}73.2 \\
(12.3)\end{array}$ & $76.8(3.5)$ & -0.629 & 0.547 \\
Height $(\mathrm{Cm})$ & $\begin{array}{c}165.6 \\
(9.5)\end{array}$ & $172.4(5.5)$ & -1.373 & 0.207 \\
BMI & $26.6(3.8)$ & $25.8(0.86)$ & 0.447 & 0.667 \\
\hline \hline
\end{tabular}

BMI: Body Mass Index; Data are presented as Mean (SD); significant difference $=\mathrm{p}<0.05$

Effect size calculations and Wilcoxon Signed Ranks Test were used to investigate the effect of the strengthening exercises with therapeutic massage on the mechanical low back pain. The effect size found to be $d=3.68$ which considered a high effect size. Therefore, the power of the test is higher than $80 \%$. This means that sample of 5 participants is enough to detect the effect of the treatment.

Wilcoxon Signed Ranks Test in the group (A) shows that the $\mathrm{P}$-value is 0.042 which is less than $\mathrm{P}=0.05$. Therefore, it concludes that there is a statistically significant difference within this group in the pain before the treatment and the pain after the treatment with strengthening exercises with therapeutic massage. Moreover, the results revealed that the average pain before the treatment was 7.60 (1.14), while after the treatment the pain decreased to $2.80(0.84)$. This means that strengthening exercises with therapeutic massage reduces mechanical low back pain significantly.

In group B, effect size calculations and Wilcoxon Signed Ranks Test were used to evaluate the effect of the mobilization techniques on the mechanical low back pain. The effect size found to be $d=2.45$ which is considerably high effect. Therefore, this demonstrates that the power of the test is way higher than $80 \%$. which means, that sample of 5 is enough to detect the effect of the mobilization techniques with therapeutic massage on the mechanical low back pain significantly.

Furthermore, Figure 1 shows the result of the Wilcoxon Signed Ranks Test in the group (B) reveals that the P-value 
is 0.034 which is less than $\mathrm{P}=0.05$. Therefore, it demonstrates that there is a statistically significant difference within the group in the pain before the treatment and the pain after the treatment with mobilization techniques and therapeutic massage. The averages score of the pain shows that the mean pain score before the treatment was 7.80 (1.30), while after the treatment the pain score decreased to 4.60 (1.14). which means that mobilization techniques with therapeutic massage reduces mechanical low back pain significantly. Table II below describes these findings.

TABLE II: COMPARISON BETWEEN PRE- AND POST VAS SCORE WITHIN

\begin{tabular}{|c|c|c|c|c|}
\hline \multicolumn{5}{|c|}{ GROUPS } \\
\hline Group & $\begin{array}{l}\text { Pre- } \\
\text { treatment } \\
\text { Mean } \pm \mathrm{SD}\end{array}$ & $\begin{array}{l}\text { Post- } \\
\text { treatment } \\
\text { Mean } \pm \mathrm{SD}\end{array}$ & $\begin{array}{l}\text { Effec } \\
\mathrm{t} \\
\text { Size }\end{array}$ & $P$ value \\
\hline $\begin{array}{l}\text { A (Strengthening } \\
\text { exercises \& } \\
\text { therapeutic } \\
\text { massage) }\end{array}$ & $7.60 \pm 1.14$ & $2.80 \pm 0.84$ & 3.68 & 0.042 \\
\hline $\begin{array}{l}\text { B (Therapeutic } \\
\text { massage and } \\
\text { mobilizations) }\end{array}$ & $7.80 \pm 1.30$ & $4.60 \pm 1.14$ & 2.45 & 0.034 \\
\hline
\end{tabular}

VAS: Visual analog scale, SD: Standard deviation.

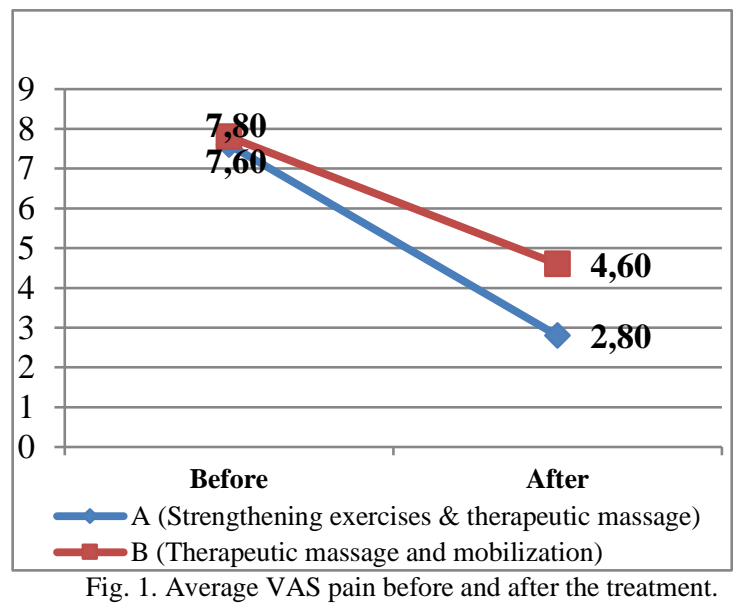

Mann-Whitney test was used to examine the pre and post results between both groups. In the pre-values, the results of the test disclosed that the P-value before the two treatments was 0.841 , which is greater than 0.05 . Thus, it concludes that there was no statistically significant difference between group A and group B of the pain before the treatment. This means that the two groups are considered identical.

However, the P-value in post-tests was equal to 0.032 , which is lesser than 0.05 . Therefore, it shows that there is statistically significant difference between groups. This also means that one of the two treatments have more effect than the other. Nevertheless, the effect size calculations suggest that the strengthening exercises with therapeutic massage have a higher effect than mobilization techniques with therapeutic massage on the mechanical low back pain. Table III below illustrates these findings.
TABLE III: COMPARISON OF PRE- AND POST- VAS SCORE IN BETWEEN GROUPS

\begin{tabular}{llll}
\hline \hline Group & $\begin{array}{l}\text { Pre- treatment } \\
\text { Mean } \pm \text { SD }\end{array}$ & $\begin{array}{l}\text { Post-treatment } \\
\text { Mean } \pm \text { SD }\end{array}$ & $\begin{array}{l}\text { Effect } \\
\text { Size }\end{array}$ \\
\hline $\begin{array}{l}\text { A (Strengthening } \\
\text { exercises \& therapeutic } \\
\text { massage) }\end{array}$ & $7.60 \pm 1.14$ & $2.80 \pm 0.84$ & 3.68 \\
$\begin{array}{l}\text { B (Therapeutic massage } \\
\text { and mobilizations) }\end{array}$ & $7.80 \pm 1.30$ & $4.60 \pm 1.14$ & 2.45 \\
P value & 0.841 & 0.032 & \\
\hline \hline
\end{tabular}

VAS: Visual analog scale, SD: Standard deviation.

"The Oswestry Disability Index (ODI)" was used to test the effect of the two treatment techniques on the low back function. Oswestry Disability Questionnaire is divided into ten sections designed to assess limitations of various activities of daily living. Each section is scored on a $0-5$ scale, 5 representing the greatest disability. The index is calculated by dividing the summed score by the total possible score (i.e. 50), which is then multiplied by 100 and expressed as a percentage.

Effect size calculations and Wilcoxon Signed Ranks Test was used to investigate scores of the low back function within groups that have been generated from the Oswestry Disability Index (ODI). For group (A), the effect size calculations show that $\mathrm{d}=5.94$ which is considered large effect size. Thus, it concludes that the power of the test is way higher than $80 \%$. This means that a sample of 5 is quite enough to detect the effect of the strengthening exercises with therapeutic massage on the low back function.

On the other side, the results of the Wilcoxon Signed Ranks Test on the group (A) showed that the P-value is equal to 0.042 . This means that there is a statistically significant difference between pre and post ODI scores. In group $\mathrm{A}$, the average ODI score before the strengthening exercises was $0.59(0.13)$. While after the treatment, the ODI score decreased to $0.20(0.8)$. Consequently, it can conclude that strengthening exercises with therapeutic massage can improve low back function significantly.

Similarly, the effect size calculations for the group (B) found that $\mathrm{d}=2.56$ which is also a large effect size. Hence, it assumes that the power of the test is way higher than $80 \%$. This means that a sample of 5is quite enough to detect the effect of mobilization techniques with therapeutic massage on low back function.

Moreover, the P-value of the Wilcoxon Signed Ranks Test for group B (tissue mobilization) was 0.043 , which is less than 0.05 . Hence, it deduces that there is a statically significant difference between pre- and post-scores of the Oswestry Disability Index (ODI). Figure 2 demonstrates the average ODI scores before and after treatment. Examining the average score of ODI before and after the mobilization techniques with therapeutic massage revealed that the average ODI score in group B before the treatment was $0.64(0.18)$. In the post measures, the average decreased to $0.35(0.11)$. This also means that mobilization techniques with therapeutic massage can reduce ODI scores significantly. This also means that mobilization techniques with therapeutic massage can improve low back function significantly. The table (4) below depicts these results. 
TABLE IV: COMPARISON OF PRE- AND POST- OSWESTRY LBP DISABILITY INDEX SCORES WITHIN GROUPS.

\begin{tabular}{|c|c|c|c|c|}
\hline Group & $\begin{array}{l}\text { Pre- } \\
\text { treatment } \\
\text { Mean } \pm \mathrm{SD}\end{array}$ & $\begin{array}{l}\text { Post- } \\
\text { treatment } \\
\text { Mean } \pm \mathrm{SD}\end{array}$ & $\begin{array}{l}\text { Effec } \\
\text { t } \\
\text { Size }\end{array}$ & $P$ value \\
\hline $\begin{array}{l}\text { A (Strengthening } \\
\text { exercises \& } \\
\text { therapeutic } \\
\text { massage) }\end{array}$ & $0.59 \pm 0.13$ & $0.20 \pm 0.08$ & 5.94 & 0.042 \\
\hline $\begin{array}{l}\text { B (Therapeutic } \\
\text { massage and } \\
\text { mobilizations) }\end{array}$ & $0.64 \pm 0.18$ & $0.35 \pm 0.11$ & 2.56 & 0.043 \\
\hline
\end{tabular}

VAS: Visual analog scale, SD: Standard deviation.

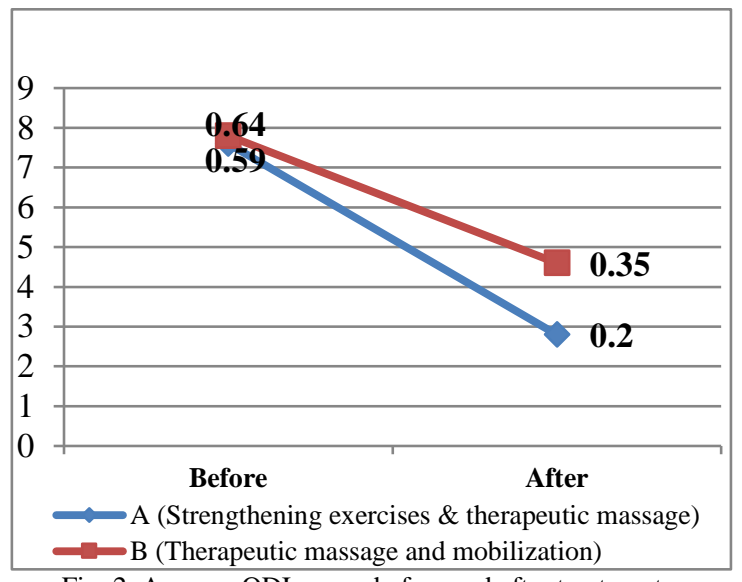

Fig. 2. Average ODI scores before and after treatment.

Mann-Whitney Test was used to compare pre and post ODI scores between groups. Pre-treatment scores revealed that the P-value was 0.690 , which is greater than 0.05 . Thus, it concludes that there is no statically significant difference between the both groups in ODI scores before the treatment. Moreover, the test on the post-treatment scores shows that the P-value was 0.056, which is a little bit higher than 0.05 , and thus it infers that there is no a statistically significant difference between group A and group B in ODI scores after the treatment. This indicates that the two treatments have the same effect and improve low back function in comparable way under the ODI scale. Table $\mathrm{V}$ below explains these findings.

TABLE V: COMPARISON OF PRE- AND POST- ODI SCORE BETWEEN GROUPS.

\begin{tabular}{llll}
\hline \hline Group & $\begin{array}{l}\text { Pre- treatment } \\
\text { Mean } \pm \mathrm{SD}\end{array}$ & $\begin{array}{l}\text { Post-treatment } \\
\text { Mean } \pm \mathrm{SD}\end{array}$ & $\begin{array}{l}\text { Effect } \\
\text { Size }\end{array}$ \\
\hline $\begin{array}{l}\text { A (Strengthening } \\
\text { exercises \& therapeutic } \\
\text { massage) }\end{array}$ & $0.59 \pm 0.13$ & $0.20 \pm 0.08$ & 3.68 \\
$\begin{array}{l}\text { B (Therapeutic massage } \\
\text { and mobilizations) }\end{array}$ & $0.64 \pm 0.18$ & $0.35 \pm 0.11$ & 2.45 \\
P value & 0.690 & 0.056 & \\
\hline \hline
\end{tabular}

VAS: Visual analog scale, SD: Standard deviation.

\section{DISCUSSION}

The study was conducted to compare the effectiveness of strengthening exercises and mobilization techniques on pain and function among patients with mechanical low back pain. Mechanical low back pain refers to back pain that arises intrinsically from the spine, intervertebral disks, or surrounding soft tissues. This includes lumbosacral muscle strain, disk herniation, lumbar spondylitis, spondylolisthesis, spondylolysis, vertebral compression fractures, and acute or chronic traumatic injury [9].

Ten patients were undertaken in the current study and they have been divided into two groups. The average age for group A was 36.6 and group B was 46.2. The average BMI for group A was 26.6 while it was 25.8 in group B. The males and females in participants were $50 \%$ males and $50 \%$ were females.

In our results reported that that strengthening exercises in effective more than mobilization techniques on pain. and there was no statistically significant difference between group A and group B in ODI score after the treatments.

Strengthening exercises aimed to maintain or improve lumbar spine stability, and improving the neuromuscular control, strength, and endurance of the muscles that are central to maintaining the dynamic spinal and trunk stability. Several groups of muscles particularly targeted the transverses abdominis and lumbar multifidi, but also other Paraspinal, abdominal, diaphragmatic, and pelvic muscles [10].

Akhtar and colleagues reported the relationship between core strengthening exercises and pain at VAS, the preinterventional mean was 9.13 and the post interventional mean was 3.08 for the group that used core strengthening exercises, Results of this study showed that both exercises proved to be effective in management of low back pain statistically but clinically there was greater pain reduction in core strengthening exercises group as compared to routine physical therapy exercises group [11].

Compared to our study as the results of strengthening exercises on pain al VAS, the pre-interventional mean was 7.60 and the post interventional mean was 2.80 , and by comparing pre-interventional and post-interventional for both groups it was concluded that there was no statistically significant difference between the two treatments. After comparison, group A and group B have no significant difference on pain threshold but effect size calculations suggest that strengthening exercises have a higher effect on pain in cases of mechanical low back pain. But by looking at the mean value for VAS for both studies indicated that results were close together.

Liddle and colleagues investigated the type and quality of exercise interventions offered to patients with chronic lowback pain (CLBP). The authors concluded that exercise had a positive effect on CLBP patients, and these positive effects were generally well maintained at follow-up [12].

Edward A. Shipton reported that physical therapy approaches in the treatment of low back pain, as results they found in chronic low back pain, the physical therapy exercise approach remains a first-line treatment, and should routinely be used [13].

Nadler and colleagues concluded that a supervised corestrengthening program emphasizing the muscles of the trunk, spine, and hip extensors resulted in a statistically no significant reduction in LBP. Although the core program had no statistically significant effect on LBP occurrence, it may have been a factor in altering the dynamics of side-toside hip strength in such a way as to have been advantageous in reducing risk for future LBP development[14].

Ahmed and colleagues reported in their studies "comparison between specific lumber mobilization and 
core-strengthening exercises with core-stability exercises Alone in mechanical low back pain" the effect of core strengthening exercises versus specific lumber mobilization on mechanical low back pain, they conveniently selected a sample 40 patients and placed into two groups. The Oswestry Disability Index (ODI) and Visual Analog Scale (VAS) for mechanical low back pain were assessment tools assessed for all patients before and after 6 weeks of physical therapy intervention. And there was a significant decrease in the VAS $(p=0.008)$ in the group who treated by core strengthening exercises and both groups shows an improvement in ODI $(\mathrm{p}=0.004)$ within both groups [15].

Jeong and colleagues reported in their studies "the effects of self-mobilization techniques for the sciatic nerves on physical functions and health of low back pain patients with lower limb radiating pain" the effects of self-mobilization techniques for the sciatic nerves on the quality of life in patients with chronic low back pain in the lower limbs accompanied by radiating pain, and they concluded that application of mobilization techniques for the sciatic nerves may promote healing of the soft tissues by stimulating the functions of the nervous system to improve nervous system adaptability and decrease sensitivity, helping to alleviate the symptoms [16].

Ghosh and colleagues showed in their studies " comparative study of muscle strengthening exercises for treatment of chronic low backache" study the outcomes of different muscle strengthening exercises in treatment of low back pain. One hundred and twenty patients in the age group of 20-40 years with mechanical low back pain were randomly divided in to two groups and instructed to perform two different types of exercises for three months (McKenzie exercise and swiss ball exercise). Patients were assessed by Visual Analogue Scale (VAS), and Oswestry Disability Index (ODI). McKenzie exercise and swiss ball exercise in patients with mechanical Low back pain reduce pain intensity, increase range of movement, and decrease functional disability. McKenzie exercise seems to have higher efficacy as compared to Swiss ball exercise [17]. These results agree our result of the effectiveness of strengthening exercises for mechanical low back pain on pain and function.

So strengthening exercises show us a better effect in reducing pain and function in patients with mechanical low back pain, so these treatments could be used in future by the physiotherapists and they focus on strengthening rather than mobilization techniques according to the results.

Our strength points in this study were that the mechanical low back pain is a common condition. Also, the period of the study was fair enough to finish it, the communication and the interactions between our group patients was good. Our weakness points were that it couldn't take enough patients because of the spread of the corona virus and three patients for each group were excluded.

\section{CONCLUSION}

This study revealed that that the strengthening exercises are effective more than mobilization techniques on pain. and also, it was found that there was no significant difference between both groups on function. Finally, strengthening exercises remain a first-line treatment, and should routinely be used for mechanical low back pain.

\section{DECLARATION OF INTEREST}

The authors declare that they have no conflict of interest.

\section{ACKNOWLEDGEMENT}

This research work was conducted within the internal research grant in its cycle for the academic year 2019/2020 awarded by Palestine Ahliya University (PAU) through the deanship of graduate studies and scientific research. We as researchers in this work emphasize that our results may not represent PAU's point of view.

We are immensely grateful for the ongoing support and encouragement by PAU represented by its president Prof. Awni Khatib and the higher administration who shared their pearls of wisdom with us in promoting scientific research culture among faculties and departments without which this work could not have been completed in such a wonderful spirit.

\section{REFERENCES}

[1] G. B. Andersson, "Epidemiological features of chronic low-back pain,” Lancet, vol. 354, no. 9178, pp. 581-585, Aug. 1999.

[2] R. Walsh and S. Paris, "Acute on chronic low back pain," in Clinical Reasoning for Manual Therapists, Elsevier, 2004, pp. 340-351.

[3] J. K. Moffett et al., "Randomised controlled trial of exercise for low back pain: clinical outcomes, costs, and preferences," BMJ, vol. 319, no. 7205, pp. 279-283, Jul. 1999

[4] A. B. Sullivan, J. Scheman, D. Venesy, and S. Davin, "The Role of Exercise and Types of Exercise in the Rehabilitation of Chronic Pain: Specific or Nonspecific Benefits," Curr. Pain Headache Rep., vol. 16 , no. 2, pp. 153-161, Apr. 2012.

[5] L. Brosseau et al., "Ottawa Panel evidence-based clinical practice guidelines on therapeutic massage for low back pain," J. Bodyw. Mov. Ther., vol. 16, no. 4, pp. 424-455, Oct. 2012.

[6] S. Kumar, K. Beaton, and T. Hughes, "The effectiveness of massage therapy for the treatment of nonspecific low back pain: a systematic review of systematic reviews," Int. J. Gen. Med., p. 733, Sep. 2013.

[7] J. Choi, G. Hwangbo, J. Park, and S. Lee, "The Effects of Manual Therapy Using Joint Mobilization and Flexion-distraction Techniques on Chronic Low Back Pain and Disc Heights," J. Phys. Ther. Sci., vol. 26, no. 8, pp. 1259-1262, 2014.

[8] I. D. Coulter et al., "Manipulation and mobilization for treating chronic low back pain: a systematic review and meta-analysis," Spine J., vol. 18, no. 5, pp. 866-879, May 2018.

[9] E. Yakut et al., "Validation of the Turkish Version of the Oswestry Disability Index for Patients With Low Back Pain," Spine (Phila. Pa. 1976)., vol. 29, no. 5, pp. 581-585, Mar. 2004.

[10] J. S. Will, D. C. Bury, and J. A. Miller, "Mechanical Low Back Pain," vol. 98, no. 7, pp. 421-428, 2018.

[11] M. W. Akhtar, H. Karimi, and S. A. Gillani, "Effectiveness of core stabilization exercises and routine exercise therapy in management of pain in chronic nonspecific low back pain: A randomized controlled clinical trial," Pakistan J. Med. Sci., vol. 33, no. 4, pp. 1002-1006, Aug. 2017.

[12] S. D. Liddle, D. G. Baxter, and J. H. Gracey, "Exercise and chronic low back pain: what works?," Pain, vol. 107, no. 1, pp. 176-190, Jan. 2004.

[13] E. A. Shipton, "Physical Therapy Approaches in the Treatment of Low Back Pain," Pain Ther., vol. 7, no. 2, pp. 127-137, Dec. 2018.

[14] S. F. Nadler, G. A. Malanga, L. A. Bartoli, J. H. Feinberg, M Prybicien, and M. DeprincE, "Hip muscle imbalance and low back pain in athletes: influence of core strengthening," Med. Sci. Sport. Exerc., vol. 34, no. 1, pp. 9-16, Jan. 2002.

[15] S. S. Urrehman, "Comparison between Specific Lumber Mobilization and Core-Stability Exercises with Core-Stability Exercises Alone in Mechanical low back pain,” Pakistan J. Med. Sci., vol. 30, no. 1, pp. 157-160, Dec. 1969

[16] U.-C. Jeong, C.-Y. Kim, Y.-H. Park, G. Hwang-Bo, and C.-W. Nam, "The effects of self-mobilization techniques for the sciatic nerves on physical functions and health of low back pain patients with lower 
limb radiating pain,” J. Phys. Ther. Sci., vol. 28, no. 1, pp. 46-50, 2016.

[17] A. Chaudhuri, P. Dhanasekaran, S. Ghosh, S. Datta, and S. Nayak, "Comparative study of muscle strengthening exercises for treatment of chronic low backache," Med. J. Dr. D.Y. Patil Univ., vol. 7, no. 4, p. 443,2014 